\title{
The employment of Patient-Reported Outcome Measures to communicate the likely benefits of surgery
}

This article was published in the following Dove Press journal: Patient Related Outcome Measures

\author{
Norman Briffa ${ }^{1,2}$ \\ 'Sheffield Teaching Hospitals, NHS \\ Trust, Sheffield, UK; ${ }^{2}$ University of \\ Sheffield, Sheffield, UK
}

Correspondence: Norman Briffa Chesterman Wing, Northern General Hospital, Herries Road, Sheffield SI7 3DH, UK

Tel +44 II4 2266777

Email N.Briffa@sheffield.ac.uk

\begin{abstract}
Decision aids as part of shared care are underutilized in surgery. Patient-Reported Outcome Measures (PROMS) are rapidly gaining interest as useful tools for various purposes in all fields of surgery. In this article, the author describes how PROMS can be used as decision aids in shared care between patients and health care workers, including surgeons.
\end{abstract}

Keywords: PROMS, shared care decisions, patient-centered care, decision aids

\section{Introduction}

Shared decision making is a process by which the choice of management of health conditions is made by the patient (with or without support persons) together with health care professionals. ${ }^{1}$ In surgery, as in other areas of therapeutic medicine, it represents the epitome of patient-centered care. Shared decision making rests upon analyzing and understanding the best evidence of risks and benefits across all options while ensuring that the patient's intentions, values and preferences are taken into account. ${ }^{2}$ Shared decision making is clearly useful when the available treatment options have no clear advantages over each other. It is also very important in situations where treatments carry class I recommendation. Early patient involvement in these situations improves compliance and expectation of outcomes, the latter being particularly important in surgery.

The Picker Institute, which first defined the term patient-centered care in 1988, identified eight indicators of quality from the viewpoint of patients - high-quality information and education being one among these. ${ }^{3}$

\section{Decision aids}

Patient decision aids are instruments created to help patients participate in decision making about treatment options. ${ }^{4}$ They provide information on the choices and help patients describe the personal value they associate with the different available options. Such aids for shared care can take the form of written material or charts and graphs presented in an electronic format such as tablet, computer or interactive screen.

Patient decision aids do not advise patients to choose a particular treatment over another. They are not meant to replace a full consultation with a health care practitioner. Instead, they prepare patients to make informed decisions based on personal values together with their practitioner. There are a number of centers around the world with expertise in patient-centered care where decision aids are curated and available online. ${ }^{5,6}$ 
In surgical practice, the use of decision aids is not as widespread as it should be. Acceptability of using aids in surgery is increasing in the surgical community. ${ }^{7,8}$ The greatest experience of decision aids in surgery has been in patients with early breast and prostate cancer where patients face difficulty in making decisions on which treatment to choose. ${ }^{9,10}$ In a comprehensive analysis of decision aids for people facing treatment, a Cochrane Collaboration group found good-quality evidence that decision aids, when compared to standard care, improve people's knowledge of treatments, and reduce the difficulty of decision making and the feeling of being uninformed or unclear about their personal values. ${ }^{11}$ Compared to usual care, decision aids stimulate patients to take an active role in decision making, and improve the perceptions of risk when chances of survival or good outcomes are included in decision aids.

The quality of decision aids used during the shared care process is now assessed using the International Patient Decision Aid Standards (IPDAS) Instrument. The IPDAS Collaboration ${ }^{4}$ represents a group of researchers, practitioners and stakeholders from around the globe and was established in 2003. This collaboration was set up to improve the quality and effectiveness of decision aids by the establishment of a shared evidence-based framework with criteria for improving their content and development, as well as evaluation.

In this article, the concept of using the results of PatientReported Outcome Measures (PROMS) as useful aids in shared care decision making in surgery is explored.

\section{PROMS}

PROMS or Patient-Reported Outcomes (US) are used to measure the patient's health. Although they were initially developed as research tools, they are now being increasingly used in everyday clinical practice to assess the outcomes of treatment. This trend will accelerate as the means of collecting data move closer to patients with use of smartphones and tablets with appropriate easy-to-use applications. In an increasingly interconnected world, data are also becoming cheaper and easier to store in the cloud.

PROMS have many uses: ${ }^{12}$

1. They are used in research to screen patients and to measure the outcomes of the intervention that is being tested. Most large grant-awarding bodies expect PROMS to be an integral part of any projects they fund.

2. Health systems use them to assess the performance of individual organizations and value-for-money of different procedures.
3. They are also used internally within the health care organizations for benchmarking and quality improvement purposes.

4. They can be used in clinical practice to monitor disease progression or response to treatment in the care of individual patients.

5. Finally, relevant to this piece, they can be used by patients to choose providers, and to choose the timing and type of treatment in shared care.

There are two types of PROMS instruments (questionnaire sets). The first type measures a patient's health in general, and the second measures the effect of a specific disease on a patient's health and well-being.

The quality and usefulness of a PROMS instrument in measuring the health of a particular group of patients are assessed using a set of psychometric tools..$^{13}$

1. Validity - ability of an instrument to measure intended outcomes with accuracy. There are three types of validity to be tested: content, construct and criterion.

2. Reliability - the consistency of the PROM results if the questionnaire is repeated in the same population at different time points.

3. Responsiveness - whether the instrument can detect changes over a time period that matters to patients.

4. Interpretability - whether the measured changes are clinically relevant.

With the advent of patient-centered care in all health care systems across the globe, the importance of using PROMS in surgery is increasing at an exponential rate. A quick search of Google Scholar for the terms surgery and PROMS in the title or abstract of research publication over a period of 15 years to 2015, revealed 259 results for the first five years, 654 for the second and 3284 for the last five years.

The surgical specialty in which PROMS instruments have been most extensively used is orthopaedics. ${ }^{14-17}$ There are however many articles on the use of PROMS in breast surgery, ${ }^{18}$ otorhinolaryngology, ${ }^{19}$ urology,${ }^{20}$ cancer surgery ${ }^{21}$ and cardiothoracic surgery. ${ }^{22}$ Widespread use of PROMS in surgery by whole health care system is restricted to England. The use of PROMS in all patients undergoing elective hip and knee replacement, groin hernia repair and varicose vein surgery has been mandated in the National Health Service by NHS England since $2008 .^{23}$

Despite the large numbers of publications featuring the use of PROMS in surgery, the majority of instruments that feature in these publications have not been subjected 
to appropriate psychometric evaluation. In the national program of the English NHS, only two of the four diseasespecific instruments have been validated, namely Oxford hip and the Oxford knee scores in patients undergoing hip and knee replacement. ${ }^{24}$ In breast surgery, the BREAST-Q questionnaire has been validated in patients undergoing breast reconstruction following mastectomy.

\section{PROMS in shared care}

The use of PROMS to assist the shared care decision making in surgery is intuitively an excellent idea. In a search of articles using the terms PROMS, shared care and surgery, only one publication was found. Legare et $\mathrm{al}^{1}$ examined the literature looking for methods to improve the adoption of shared care decision making by health care professional workers (including surgeons). Some of the studies reviewed by the team used PROMS to assess patients' responses to the shared care process itself rather than to measure the outcomes of treatment. Gray et $\mathrm{a}^{25}$ have extensively used an online electronic questionnaire system in their urogynecology practice. Graph summaries of the result of questionnaires are used in the shared care process and consent prior to surgery.

In shared care decision making in surgery, PROMS can be used in two ways:

1. They can be used as a guide to the indication for and timing of surgery. The patient could be shown the evidence of symptom deterioration in a clear and concise manner with graphical representation of patient's own data from sequential preoperative PROMS. PROMS are most useful when used in this way, that is, to monitor and guide individual patient's treatment. An excellent example of this is the Swedish Rheumatology Quality Registry. ${ }^{12}$ This was established in 1995 and contains data from 66,000 patients who represent $85 \%$ of all people in Sweden with rheumatoid arthritis. PROMS are tracked over time in relation to ongoing treatment. Data generated by patients are fed into a dashboard which is used to guide treatment, shared decision making and self-management. There is evidence that this approach has significantly decreased the incidence of acute exacerbations and permanent joint damage. ${ }^{26}$

2. Data from collated large PROMS databases could be used in a graphic summative fashion to illustrate the results of different ways (operative or conservative) of treating a specific condition. Such large amounts of PROMS data for specific surgical procedures would only be available from large programs such as the mandated English NHS one. The huge amounts of data would make it possible for the illustrative outputs to be made more granular and specific to the individual patients' characteristics including age, gender, weight and disease.

\section{Conclusion}

The idea of using PROMS data to aid shared decision making prior to surgery is one which is worth pursuing. It is important that PROMS instruments used for this purpose have been psychometrically evaluated with the group of patients they are to be used in. The quality of the PROMS instrument and the way the results are presented as a decision aid need to be tested using the IPDAS instrument.

Current evidence for the use of PROMS as decision aids is scant. This area should therefore be a fertile area for research in future. As funding for patient-centered care from bodies such as the Patient-Centered Outcomes Research Institute in the USA and the National Institute for Health Research in the UK increases, research teams from all surgical disciplines should take this opportunity to investigate the use of increasing amount of available PROMS data in shared decision making and patient-centered care.

\section{Disclosure}

The author reports no conflicts of interest in this work.

\section{References}

1. Legare F, Stacey D, Turcotte S, et al. Interventions for improving the adoption of shared decision making by healthcare professionals. Cochrane Database Syst Rev. 2014;(9):CD006732.

2. Ting HH, Brito JP, Montori VM. Shared decision making: science and action. Circ Cardiovasc Qual Outcomes. 2014;7:323-327.

3. Barry MJ, Edgman-Levitan S. Shared decision making - the pinnacle of patient-centered care. $N$ Engl J Med. 2012;366:780-781.

4. International Patient Decision Aids Standards (IPDAS) Collaboration. Available from: http://ipdas.ohri.ca/index.html. Accessed December 30, 2017.

5. EBSCO Health. Option Grid ${ }^{\mathrm{TM}}$ decision aids. Available from: http:// optiongrid.org/. Accessed December 30, 2017.

6. Ottawa Hospital Research Institute. Patient Decision Aids. Available from: https://decisionaid.ohri.ca/. Accessed December 30, 2017.

7. Adam JA, Khaw F-M, Thomson RG, Gregg PJ, Llewellyn-Thomas HA Patient decision aids in joint replacement surgery: a literature review and an opinion survey of consultant orthopaedic surgeons. Ann R Coll Surg Engl. 2008;90:198-207.

8. Jayadev C, Khan T, Coulter A, Beard DJ, Price AJ. Patient decision aids in knee replacement surgery. Knee. 2012;19:746-750.

9. Violette PD, Agoritsas T, Alexander P, et al. Decision aids for localized prostate cancer treatment choice: systematic review and meta-analysis. CA Cancer J Clin. 2015;65:239-251.

10. Zdenkowski N, Butow P, Tesson S, Boyle F. A systematic review of decision aids for patients making a decision about treatment for early breast cancer. Breast. 2016;26:31-45.

11. Stacey D, Legare F, Col NF, et al. Decision aids for people facing health treatment or screening decisions. Cochrane Database Syst Rev. 2014;4:CD001431.

12. Nelson EC, Eftimovska E, Lind C, Hager A, Wasson JH, Lindblad S Patient reported outcome measures in practice. BMJ. 2015;350:g7818. 
13. Holmes C, Briffa N. Patient-Reported Outcome Measures (PROMS) in patients undergoing heart valve surgery: why should we measure them and which instruments should we use? Open Heart. 2016;3:e000315.

14. Dietvorst M, Reijman M, van Groningen B, van der Steen MC, Janssen RPA. PROMs in paediatric knee ligament injury: use the Pedi-IKDC and avoid using adult PROMs. Knee Surg Sports Traumatol Arthrosc. Epub 2017 Sep 19.

15. Stokes OM, Cole AA, Breakwell LM, Lloyd AJ, Leonard CM, Grevitt M. Do we have the right PROMs for measuring outcomes in lumbar spinal surgery? Eur Spine J. 2017;26:816-824.

16. Ayers DC. Implementation of Patient-reported Outcome Measures in total knee arthroplasty. J Am Acad Orthop Surg. 2017;25 Suppl 1:S48-S50.

17. Gagnier JJ. Patient reported outcomes in orthopaedics. J Orthop Res. 2017;35:2098-2108.

18. Cohen WA, Mundy LR, Ballard TNS, et al. The BREAST-Q in surgical research: a review of the literature 2009-2015. J Plast Reconstr Aesthet Surg. 2016;69:149-162.

19. Barone M, Cogliandro A, Di Stefano N, Tambone V, Persichetti P. A systematic review of patient-reported outcome measures after rhinoplasty. Eur Arch Otorhinolaryngol. 2017;274:1807-1811.

20. Clark R, Welk B. Patient reported outcome measures in neurogenic bladder. Transl Androl Urol. 2016;5:22-30.
21. Straatman J, van der Wielen N, Joosten PJ, et al. Assessment of patientreported outcome measures in the surgical treatment of patients with gastric cancer. Surg Endosc. 2016;30:1920-1929.

22. Holmes C, Briffa N. Evaluation of the effect of treatment in patients undergoing heart valve surgery in Sheffield using patient reported outcome measures. Int J Surg. 2015;18:244.

23. Black N. Patient reported outcome measures could help transform healthcare. BMJ. 2013;346:f167.

24. Harris K, Dawson J, Gibbons E, et al. Systematic review of measurement properties of patient-reported outcome measures used in patients undergoing hip and knee arthroplasty. Patient Relat Outcome Meas. 2016;7:101-108.

25. Gray TG, Alexander C, Jones GL, Tidy JA, Palmer JE, Radley SC. Development and psychometric testing of an Electronic PatientReported Outcome Tool for Vulval Disorders (ePAQ-Vulva). J Low Genit Tract Dis. 2017;21:319-326.

26. Svensk Reumatologis Kvalitetsregister [Swedish Rheumatology Quality Registry]. Annual report 2012. Available from: http://srq.nu/ srqny/wp-content/uploads/2014/10/Appendix-1.1-Swedish-e-healthLandscape-4-30-14-FINAL-1.pdf. Accessed December 30, 2017. Danish.
Patient Related Outcome Measures

\section{Publish your work in this journal}

Patient Related Outcome Measures is an international, peer-reviewed, open access journal focusing on treatment outcomes specifically relevant to patients. All aspects of patient care are addressed within the journal and practitioners from all disciplines are invited to submit their work as well as healthcare researchers and patient support groups.

\section{Dovepress}

The journal is included in PubMed. The manuscript management system is completely online and includes a very quick and fair peer-review system. Visit http://www.dovepress.com/testimonials.php to read real quotes from published authors. 